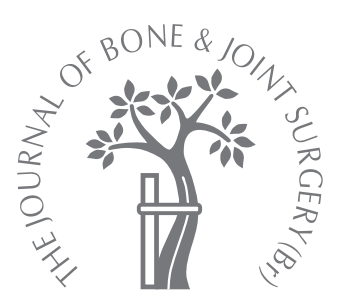

R. T. Steffen, S. R. Smith, J. P. G. Urban, P. McLardy-Smith, D. J. Beard, H. S. Gill, D. W. Murray

From the Nuffield Orthopaedic Centre, Oxford, England

R. T. Steffen, MRCS Clinical Research Fellow P. McLardy-Smith, FRCS, Consultant Orthopaedic Surgeon

D. J. Beard, DPhil,

University Research Lecturer H. S. Gill, DPhil, University Research Lecturer D. W. Murray, MD, FRCS(Orth), Professor of Orthopaedic Surgery Department of Orthopaedic Surgery

Nuffield Orthopaedic Centre, Windmill Road, Oxford OX3 7LD, UK.

S. R. Smith, DPhil, PostDoctoral Research Scientist J. P. G. Urban, PhD, Senior ARC Research Fellow Department of Physiology University of Oxford, Parks Road, Oxford OX1 3PT, UK

Correspondence should be sent to Dr H. S. Gill; e-mail: richie.gill@ndos.ox.ac.uk

(C)2005 British Editorial Society of Bone and Joint Surgery doi:10.1302/0301-620X.87B11. $16780 \$ 2.00$

$J$ Bone Joint Surg [Br] 2005:87-B:1468-74.

Received 31 May 2005; Accepted 6 July 2005

\section{The effect of hip resurfacing on oxygen concentration in the femoral head}

\begin{abstract}
We inserted an electrode up the femoral neck into the femoral head of ten patients undergoing a metal-on-metal hip resurfacing arthroplasty through a posterior surgical approach and measured the oxygen concentration during the operation. In every patient the blood flow was compromised during surgery, but the extent varied. In three patients, the oxygen concentration was zero at the end of the procedure. The surgical approach caused a mean $60 \%$ drop $(p<0.005)$ in oxygen concentration while component insertion led to a further $20 \%$ drop $(p<0.04)$. The oxygen concentration did not improve significantly on wound closure. This study demonstrates that during hip resurfacing arthroplasty, patients experience some compromise to their femoral head blood supply and some have complete disruption.
\end{abstract}

Primary total hip replacement (THR) in young and active patients does not necessarily provide a lasting solution. ${ }^{1,2}$ It is well recognised that there is a high rate of failure in this group. ${ }^{3}$ To overcome the challenges of high-demand patients, technical and design developments have been proposed ${ }^{4-6}$ and recently, there has been a renewed interest in resurfacing arthroplasty. The first short- and medium-term survival studies of the new generation of metalon-metal hip resurfacing devices have shown favourable survival rates, ${ }^{7,8}$ attributed to better metallurgy and modern manufacturing methods.

However, a major reason for concern is failure of the femoral component because of fracture of the femoral neck reported to occur in between $0 \%$ and $12 \%$ of patients (Table I). ${ }^{8-15}$ Recently, Little et $\mathrm{al}^{16}$ reported an incidence of approximately $2 \%$ in a series of 377 patients; the fractured necks displayed established osteonecrosis although, at the time of surgery, there was no histological evidence of this. Treacy, McBryde and Pynsent ${ }^{17}$ also noted that secondary avascular necrosis (AVN) could occur after resurfacing of the hip, although with a very low incidence. In contrast, Milgram and Rana ${ }^{18}$ reported evidence of AVN of the femoral head in 29 of 32 failed hip resurfacing arthroplasties; the extent of the AVN ranged from focal to widespread. AVN undoubtedly plays a role in any failure of the femoral component but its importance is still disputed. ${ }^{19}$
Table I. Incidence of femoral neck fracture after resurfacing arthroplasty of the femoral head as reported by different authors

\begin{tabular}{lcl}
\hline Author/s & $\begin{array}{c}\text { Number } \\
\text { of hips }\end{array}$ & $\begin{array}{l}\text { Incidence of femoral } \\
\text { neck fracture (\%) }\end{array}$ \\
\hline${\text { Capello et } \mathrm{al}^{9}}^{9}$ & 68 & 12 \\
Freeman et al $^{10}$ & 108 & 7 \\
Trentani and Vaccarino $^{11}$ & 70 & 5 \\
Gerard $^{14}$ & 337 & 0.4 \\
Beaulé et al $^{12}$ & 42 & 2.4 \\
Pearson et al $^{13}$ & 342 & 1.8 \\
Daniel et al $^{8}$ & 446 & $0^{*}$ \\
Shimmin and Back $^{15}$ & 3497 & 1.5 \\
Little et al $^{16}$ & 377 & 2.1 \\
Treacy et al $^{17}$ & 144 & 0.7 \\
\hline
\end{tabular}

* one revised for avascular necrosis femoral head

Tissue oxygenation and perfusion can be assessed with needle electrodes. Albery et al, ${ }^{20}$ in 1978, first described this measurement technique, which enables the simultaneous detection of oxygen and nitrous oxide concentrations in either gas or blood. The method was advanced further in an in vitro study by Hahn et $\mathrm{al}^{21}$ who investigated gas concentrations in electrolyte solutions. The first in vivo application of intravascular electrodes in anaesthetised dogs was reported by Brooks et al. ${ }^{22}$ Further modifications allowed oxygen and nitrous oxide concentrations to be measured in muscle and intervertebral disc tissue $\mathrm{e}^{23-27}$ in humans. To our knowledge, however, these have not previously been measured in bone.

The aim of our study was to develop a technique for measuring oxygen and nitrous oxide 


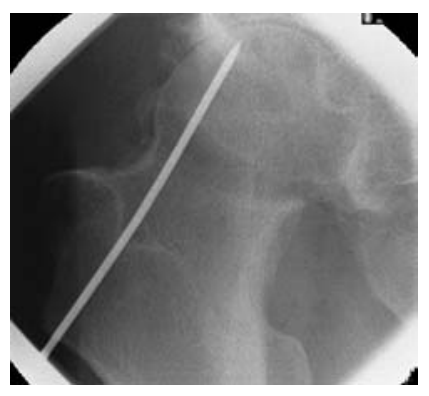

Fig. 1a

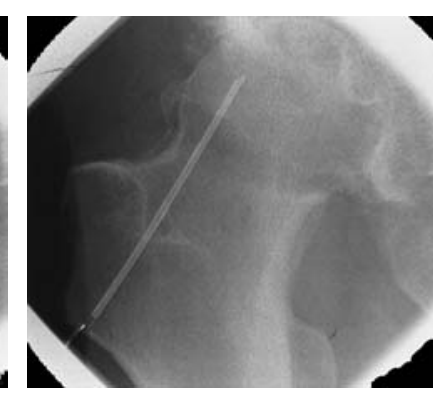

Fig. 1b
Fluoroscopic images to show a) insertion of the Kirschner-wire and b) placement of the measurement electrode.

in bone. Secondly, we planned to continuously monitor the concentration of these gases during a series of resurfacings in order to determine if the blood flow was compromised and, if so, to determine at which stage of the operation this occurred.

\section{Patients and Methods}

Fifteen patients undergoing routine metal-on-metal hip resurfacing for primary osteoarthritis were included in the study which had ethical approval and informed consent was obtained from each patient. All procedures were performed under general anaesthesia through an extended posterior approach; the patients received either the Birmingham resurfacing arthroplasty (Smith and NephewMMT, Birmingham, UK) or the Conserve Plus (Wright Medical, Memphis, Tennessee). There were ten men and five women. Their mean age was 55.8 years (24 to 70 ).

Principle of measurement. We assessed blood flow on the basis of the concentrations of oxygen $\left(\mathrm{O}_{2}\right)$ and nitrous oxide $\left(\mathrm{N}_{2} \mathrm{O}\right)$. During anaesthesia the patient receives a mixture of these two gases $\left(60 \% \mathrm{O}_{2}, 40 \% \mathrm{~N}_{2} \mathrm{O}\right)$. If the blood flow to the tissues is interrupted, the oxygen present is metabolised rapidly and the measured decrease in concentration reflects the reduced blood flow. Nitrous oxide is not metabolised, any reduction in its concentration after blood flow reduction being a result of diffusion.

In our study we applied a modification of the technique described by Brooks et al. ${ }^{22}$ Silver (Ag) electrodes, when correctly polarised, generate a current, which is proportional to the concentration of the target gas. Selecting the correct polarisation voltage (with respect to a silver/silver chloride (Ag/AgCI) reference electrode), selects the gas to which an electrode is sensitive. Switching between the two appropriate polarising voltages allows a single electrode to be used for both $\mathrm{O}_{2}$ and $\mathrm{N}_{2} \mathrm{O}$ measurements. The measurement and reference electrodes were custom-manufactured with $2 \mathrm{~m}$ of signal wire soldered to each electrode. The electrode assemblies were sterilised using gamma-irradiation.

All the measurement electrodes were calibrated pre-operatively in a solution of phosphate-buffered normal saline with known, dissolved concentrations of $\mathrm{O}_{2}$ and $\mathrm{N}_{2} \mathrm{O}$. The electrodes were polarised by a medical grade potentiostat system, which incorporated an opto-electronic head-stage in order to ensure electrical isolation of the patient from the power supply (potentiostat control box, Model MEC V1; opto-electronic head-stage, Model MHS V1; power supply unit; Model MPS V1, EMS, Newbury, UK).

The electrode output current (in $\mathrm{mA}$ ) was recorded on a computer workstation using a commercial analogue-to-digital converter (PowerLab, ADInstruments, Chalgrove, UK) at a data collection rate of $10 \mathrm{~Hz}$.

Measurement protocol. After anaesthesia had been induced, the patient was placed in the lateral decubitus position and their pelvis stabilised by a padded support. A standard, extended posterior approach was performed and, once the fascia lata was divided, a Kirschner (K-) wire (diameter 2 $\mathrm{mm}$ ) was introduced into the femoral neck below the greater trochanter. It was then advanced up the femoral neck under fluoroscopic guidance so that the end of the wire was positioned in the superolateral quadrant of the femoral head (Fig. 1). It was then removed. The cortical bone around the mouth of the resulting tunnel was widened slightly with a drill, and a size $14 \mathrm{Ag}$ measurement electrode was then introduced. Correct electrode placement was confirmed fluoroscopically (Fig. 1). An Ag/AgCI reference electrode was then placed within gluteus medius and both sets of electrodes were connected to the potentiostat and data collection systems, using the 2-m signal wires to reach beyond the sterile field. The measurement system is shown schematically in Figure 2.

Baseline measurements were established for $\mathrm{O}_{2}$ and $\mathrm{N}_{2} \mathrm{O}$. Valid baseline measurements were assured by detection of at least two repeatable values for each gas concentration. Following this the anaesthetist increased the $\mathrm{N}_{2} \mathrm{O}$ concentration in the anaesthetic gas from $40 \%$ to $60 \%$ for a two-minute interval. The purpose of this $\mathrm{N}_{2} \mathrm{O}$ pulse was to ensure that the measurement electrode could track changes in the gas concentrations reliably. After the cessation of this $\mathrm{N}_{2} \mathrm{O}$ pulse, the surgeon began blunt separation of the fibres of gluteus maximus whose tendon was divided at its insertion into the linea aspera. The short external rotator muscles, including piriformis and quadratus femoris, were divided, the capsule was incised and the hip was dislocated. The surgical approach ended with a circumferential division and partial excision of the capsule.

Two variations in technique were subsequently used. For some patients, the preparation and insertion of the acetabular component was performed before that of the femoral component (group A). For the remaining patients femoral preparation was performed first, followed by preparation and insertion of the acetabular component and, finally, insertion of the femoral component (group F). These variations in technique were a result of surgeon preference and gave the opportunity to review any differences in intraoperative femoral head perfusion between the two groups.

The electrodes were maintained in the measurement position until the final reduction of the resurfaced joint and 


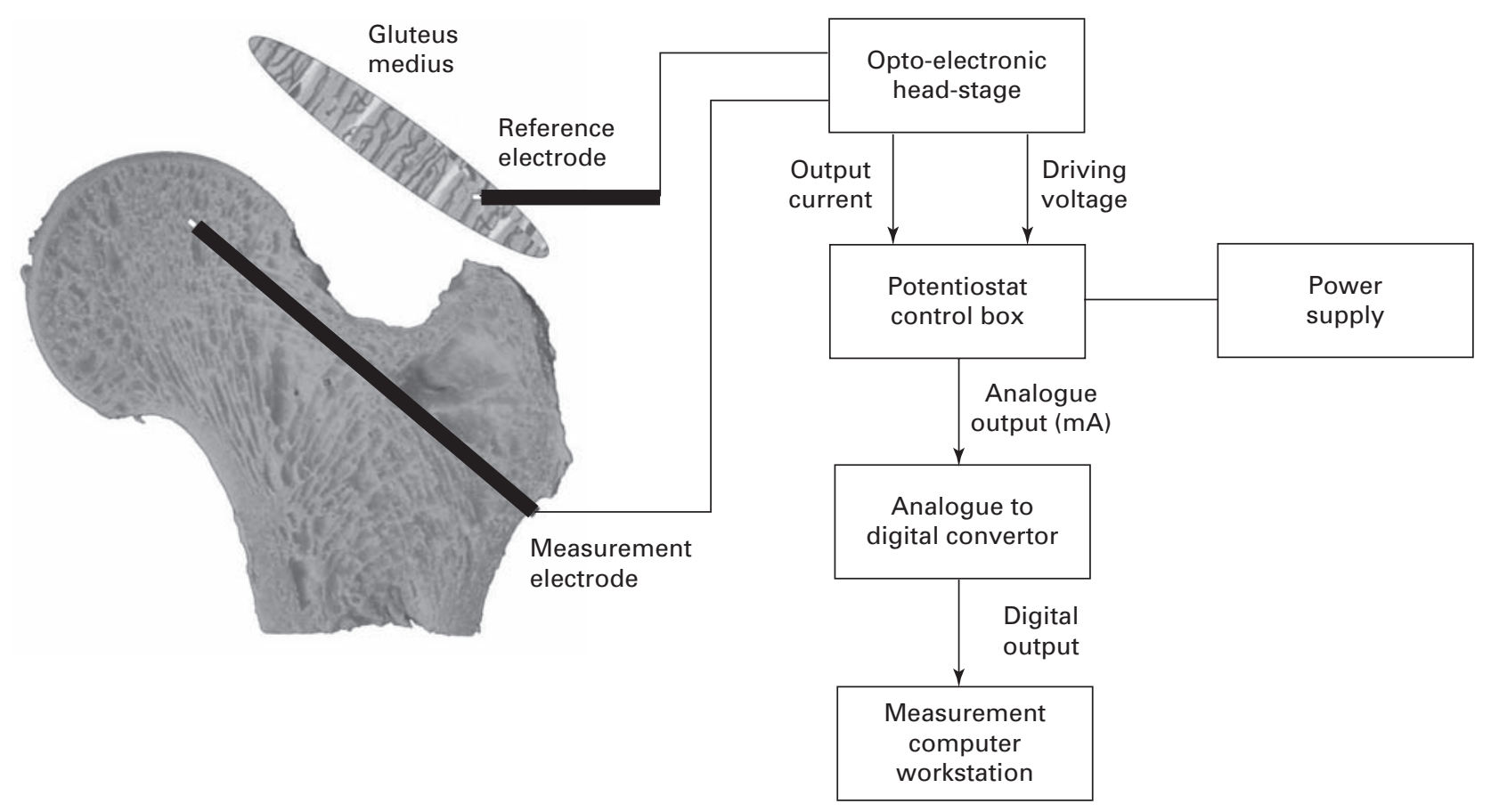

Fig. 2

The measurement system.

reconstruction of the posterior capsule and short external rotators had been performed. Validation measurements were made after removal of the electrodes and a further recalibration was undertaken in the laboratory at a later stage. If any intra-operative damage to the electrodes was detected, those measurements were excluded.

Electrode validation. The electrodes were removed and placed into a saline solution containing $20 \% \mathrm{O}_{2}$ and the $\mathrm{O}_{2}$ concentration was recorded. This validation procedure established that the accuracy of the measurement was within $10 \%$.

Analysis. The measurements of intra-operative current were converted into $\mathrm{O}_{2}$ and $\mathrm{N}_{2} \mathrm{O}$ concentrations on the basis of each individual electrode calibration. Baseline concentrations were considered to be those measured immediately after insertion of the electrodes. The gas concentrations were represented as a percentage of the baseline measurements. The various surgical steps were grouped and used as a standardised event-based timeline (rather than a chronological timeline) in order to compare results between patients. The groups were as follows: 1) start, measurements taken immediately after insertion of the electrodes; 2) approach, this included the muscle/soft-tissue division, capsulotomy and dislocation. The measurement was made at the end of the anterior capsulotomy; 3) implant insertion, this included the preparation of both the femur and the acetabulum as well as the insertion and fixation of the components; 4) relocation, the resurfaced joint was reduced and the posterior capsule and short external rotators were repaired. A measurement was taken before closure of the fascia lata.

Statistical analysis was performed with a Wilcoxon signed-rank test for matched pair analysis using the Statistics Toolbox version 4 available in Matlab version 6.5 (The MathWorks Inc., Natick, Massachusetts). Oxygen concentrations at the following pairs of surgical time points were tested as matched pairs: 1) start and approach;2) approach and implant insertion; 3 ) implant insertion and relocation.

The decrease in $\mathrm{O}_{2}$ concentration was calculated for the insertion of both the femoral and acetabular components. In addition, the effect of the order of preparation, i.e. between groups A and F, was investigated using the signedrank test.

\section{Results}

There were no surgical complications related to the measurements of blood gas concentration in the femoral head. Successful data collection was achieved in ten patients; data from five patients was discarded because of damage to the electrodes during the procedure. Of the ten successful measurements, five were in group $\mathrm{F}$ and five were in group $\mathrm{A}$.

In all cases the $\mathrm{N}_{2} \mathrm{O}$ pulse given in the inhaled gas resulted in an increase in measured $\mathrm{N}_{2} \mathrm{O}$ in the bone, indicating that there was blood flow. However, the rate of increase varied from patient to patient, indicating differences in the blood flow to the femoral head.

The pattern of change in gas concentration varied between the patients. Taking an illustrative individual case, 


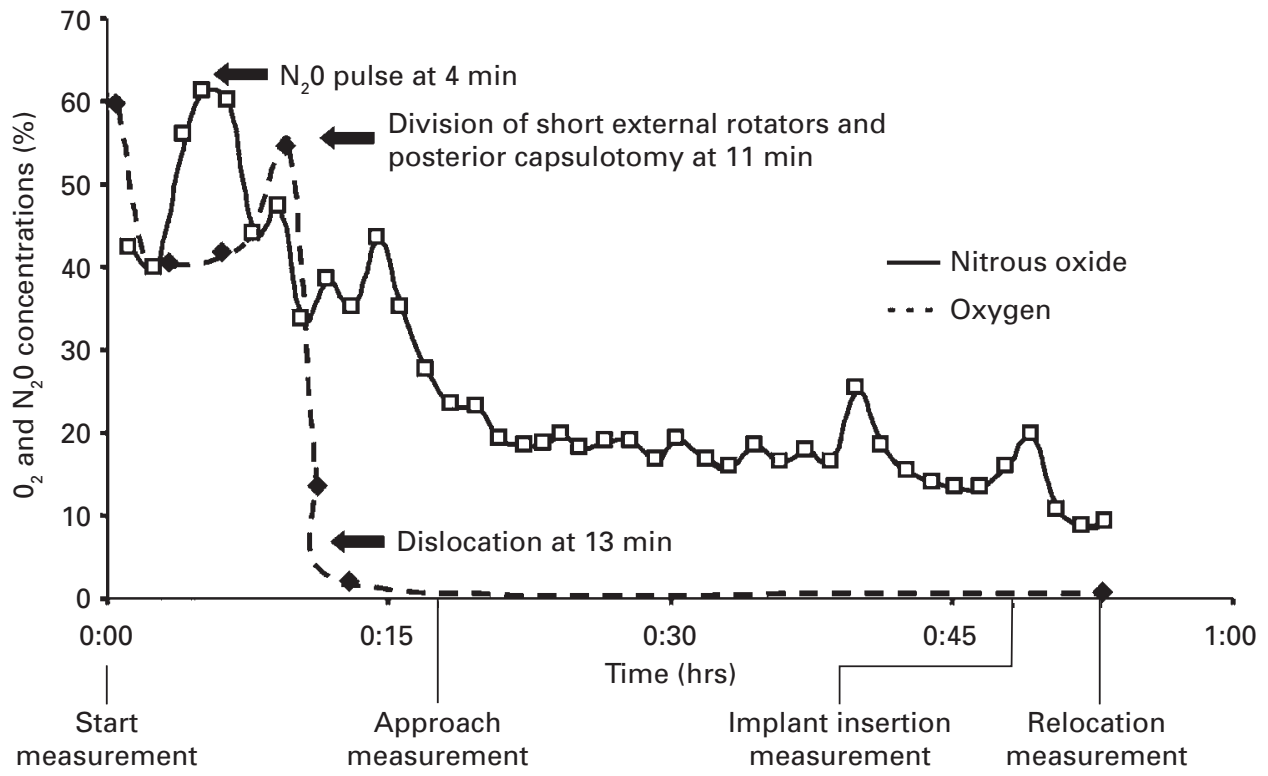

Fig. 3

Illustrative example of oxygenation drop during surgical approach, without recovery.

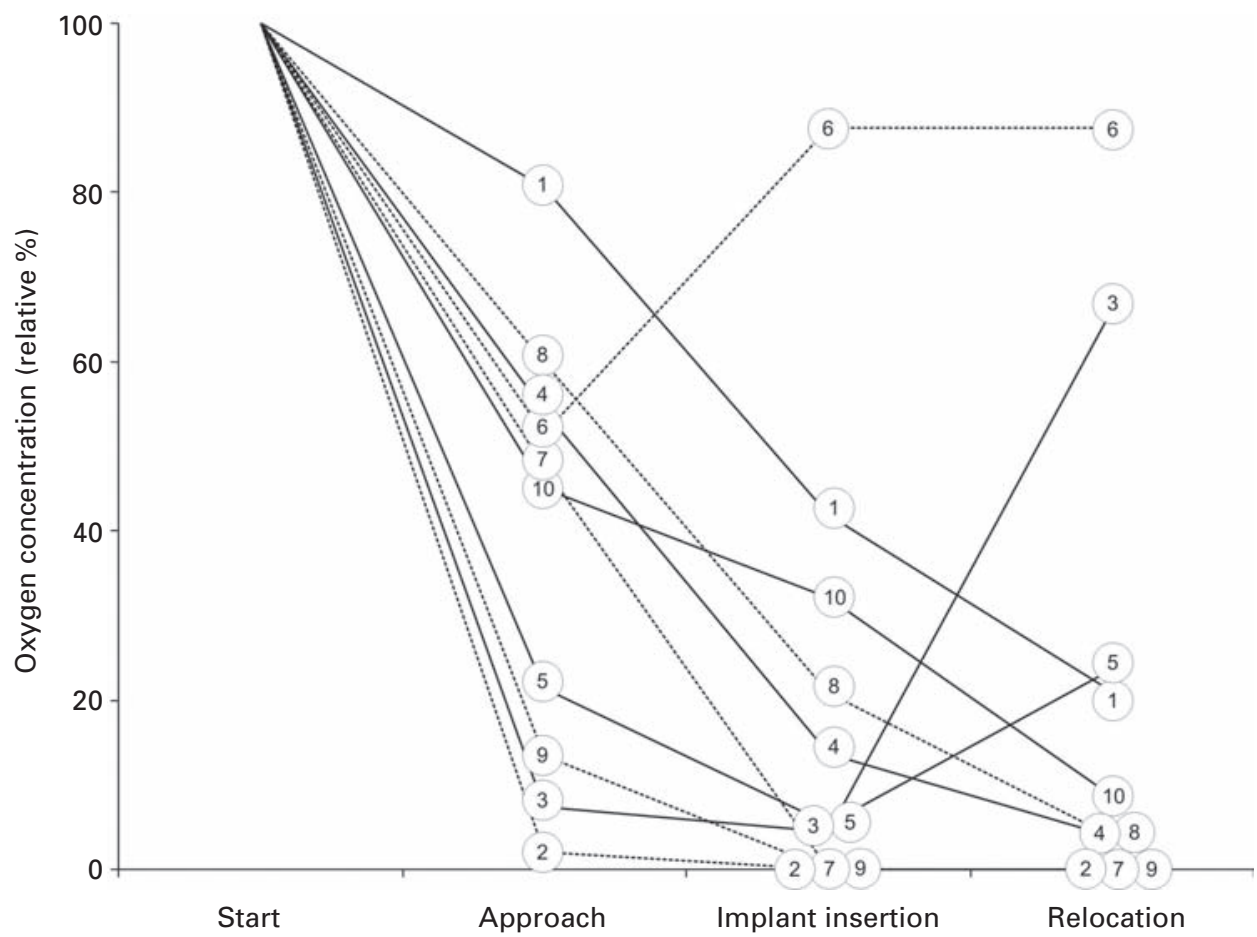

Fig. 4

Intra-operative oxygenation changes for each patient. The numbers on the curves identify individual patients, lines being alternately dashed and solid solely for clarity. 


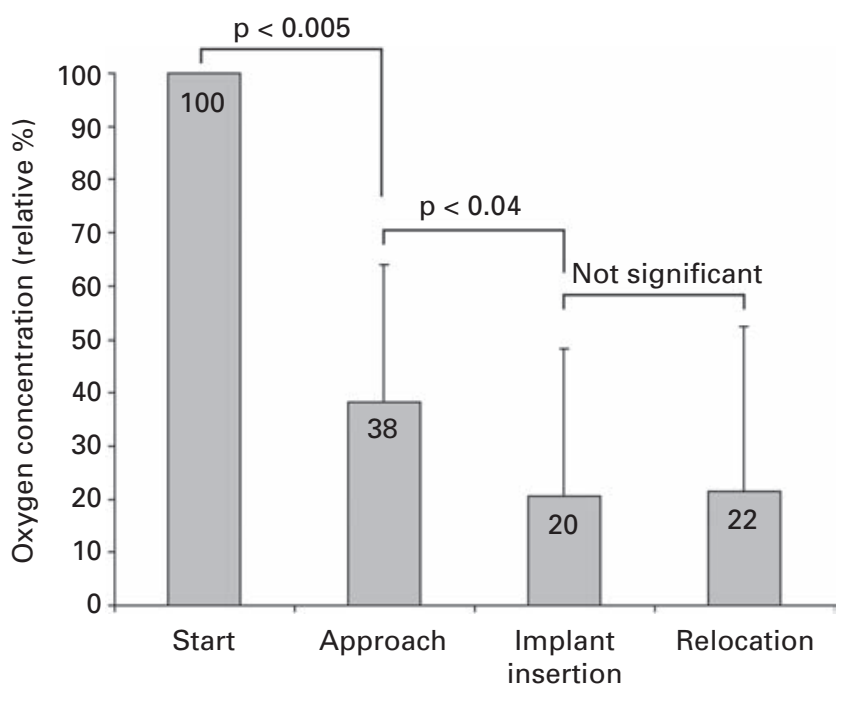

Fig. 5

Summary of oxygenation changes for all patients; the results of the Wilcoxon signed-rank test for matched pair analyses are given.

the baseline concentrations were seen in the same 60:40 ratio of $\mathrm{O}_{2}$ and $\mathrm{N}_{2} \mathrm{O}$ provided by the anaesthetic machine (Fig. 3). During the $\mathrm{N}_{2} \mathrm{O}$ pulse, an increase in $\mathrm{N}_{2} \mathrm{O}$ concentration was observed, with a synchronous decrease in $\mathrm{O}_{2}$ concentration; as the pulse ended, $\mathrm{N}_{2} \mathrm{O}$ levels dropped and $\mathrm{O}_{2}$ levels increased. A dramatic reduction in $\mathrm{O}_{2}$ concentration was seen with muscle division and capsulotomy. In this case, $\mathrm{O}_{2}$ concentration dropped to zero after dislocation and showed no recovery for the remainder of the procedure. The $\mathrm{N}_{2} \mathrm{O}$ concentration showed a continuous, steady decline throughout the procedure, dropping to approximately a quarter of the baseline value at the point of relocation.

There was considerable variation in $\mathrm{O}_{2}$ concentration levels during surgery (Fig. 4). In all cases there was a substantial fall in $\mathrm{O}_{2}$ concentration as a result of the approach. In most patients it continued to fall during the procedure. At the end of the procedure, three patients had zero $\mathrm{O}_{2}$ concentration, four had very low levels and three had some degree of recovery. The largest change in $\mathrm{O}_{2}$ concentration occurred during the approach, when it dropped to $38 \%$ of baseline (SD 26\%); this was a highly significant reduction ( $\mathrm{p}$ $<0.005$; Fig. 5). At the end of the implant insertion step, $\mathrm{O}_{2}$ concentration reduced again, dropping to $20 \%$ of baseline (SD 28\%); this change was also significant $(\mathrm{p}<0.04)$. It then rose slightly, reaching $22 \%$ of baseline after the relocation step; this was not significant $(\mathrm{p}=0.69)$.

The order in which the components were inserted had no significant effect on the outcome $(p=0.54)$. In the five patients in whom the acetabulum was prepared first (group A), the decrease in $\mathrm{O}_{2}$ concentration associated with implantation was $15 \%$ (SD 36\%). In the five in whom the femur was prepared first (group F), the decrease was $20 \%$ (SD $8 \%$ ). In all ten patients the mean decrease in oxygen concentration associated with acetabular preparation was $21 \%$ (SD $28 \%$ ); this was statistically significant $(\mathrm{p}=0.037)$. There was, however, no significant change in concentration during femoral preparation ( $3 \%$ decrease, $S D 28 \%, \mathrm{p}=0.67)$.

\section{Discussion}

In all ten patients in this study, there was a decrease in oxygenation concentration in the femoral head during the operation. In three patients, by the end of the procedure, the $\mathrm{O}_{2}$ concentration was zero, suggesting that the blood supply to the femoral head had been completely disrupted. This has important implications for hip resurfacing as it suggests that the damage to the blood supply during the operation is more severe than is generally believed. Fortunately, in the majority of patients the blood supply to the femoral head must recover spontaneously as positron emission tomography scanning of the head at one year suggests there is adequate perfusion. ${ }^{28}$ However, it is likely that in some patients the blood supply does not recover adequately which may be the explanation for many of the complications associated with the resurfacing femoral component. For example, a compromised blood supply may explain many of the femoral neck fractures and cases of loosening associated with avascular necrosis. It is therefore important to understand why the blood supply is damaged by the operation and how this can be prevented.

The femoral head and neck obtain their blood supply from various sources, as described by Trueta and Harrison in $1953 .{ }^{29}$ The main supply is from the deep branch of the medial femoral circumflex artery. This is variable, but terminates in two to four vessels. One branch arises adjacent to the proximal border of quadratus femoris. The main division passes anterior to the tendons of the obturator internus and gemelli. It perforates the joint capsule at the level of the superior gemellus and divides into terminal branches which pass along and enter the femoral neck. ${ }^{30}$ There may also be some blood supply to the femoral head from the ligamentum teres and from interosseous anastomoses within the metaphysis. During metal-on-metal hip resurfacing through an extended posterior approach, the branches of the medial femoral circumflex artery which pass along the short external rotators are likely to be destroyed. In addition, if there is any blood supply from the ligamentum teres this will also be destroyed.

We found that the surgical approach resulted in a mean $62 \%$ decrease in oxygenation of the femoral head. Most of this decrease appeared to be a result of the division of the short rotators and capsule, confirming that the deep branch of the medial femoral circumflex artery provides the most important blood supply to the femoral head. If the femoral head and the proximal femoral neck are rendered avascular, and if this does not recover, avascular necrosis will occur. In the long term, dead bone may fail from multiple fatigue fractures which can, in turn, lead to femoral head collapse and loosening. In addition, in the short term, there may be 
bony resorption at the interface between viable and dead bone as part of the process of creeping substitution; this will temporary weaken the femoral neck and may precipitate a fracture.

In order to prevent complications relating to the femoral component the surgical technique should be modified so as to minimise damage to the blood supply. The majority of damage occurs during the approach and results from division of the blood vessels in the region of the short external rotators, muscles which have to be divided during a posterior approach. Consideration should, therefore, be given to using different approaches, and studies should be undertaken to investigate the effect these have on the blood supply to the femoral head. Our study also demonstrated that acetabular preparation resulted in significant decrease in blood supply to the femoral head. This may be related to the position of the femur during acetabular preparation and consideration should, therefore, be given to altering this.

The gas electrode-based system developed in this study appears to be useful for assessing oxygenation in bone. In every patient the $\mathrm{N}_{2} \mathrm{O}$ pulse was detected by the electrode, indicating that the technique is able to monitor the gases in the bone continuously. The technique was difficult to develop, although once finalised validation suggested that it could measure $\mathrm{O}_{2}$ concentration to within $10 \%$. The electrode assesses the gaseous concentration within a small volume of bone although the size of this is unknown. As there was variation in the $\mathrm{O}_{2}$ concentration measured as soon as the electrode was implanted, it is likely that in osteoarthritis the $\mathrm{O}_{2}$ concentration within the femoral head is variable.

There are many potential applications for a reliable method of measuring and monitoring oxygen concentration and blood flow in bone. For example, a measurement of oxygen concentration following a fractured neck of femur or fractured talus might influence subsequent surgical management. Similarly, monitoring of blood flow during reduction of a slipped femoral capital epiphysis would be advantageous. The electrochemical method developed for this study, in addition to measuring $\mathrm{O}_{2}$ concentration, can be used to measure absolute blood flow. This is performed by measuring the rate of change of $\mathrm{N}_{2} \mathrm{O}$ in the bone following an $\mathrm{N}_{2} \mathrm{O}$ pulse in the inhaled anaesthetic gases. In this study we did not measure absolute blood flow, as serial measurements would have extended the length of the procedure significantly. Instead, the measurements of $\mathrm{O}_{2}$ concentration gave an indirect measure of blood flow. An alternative method of assessing femoral head perfusion has been described by Notzli et $\mathrm{al}^{31}$ during dislocation of the hip, using laser Doppler flowmetry with a high-energy laser, although this could not easily be used to monitor vascularity throughout an operation.

During metal-on-metal hip resurfacing arthroplasty using an extended posterior approach, there is a highly significant reduction in femoral head oxygenation $(62 \%)$ during the surgical approach. There is a further small decline in $\mathrm{O}_{2}$ concentration during the rest of the operation and, in about one-third of patients the femoral head appears to be completely avascular by the end of the operation. Our findings clearly raise concerns about the viability of the femoral head and neck after hip resurfacing. They may also explain some of the complications of hip resurfacing such as femoral neck fracture and AVN. The technique for assessing $\mathrm{O}_{2}$ concentration should be used in further studies in order to investigate whether alternative surgical approaches are less damaging to the blood supply.

\section{Supplementary Material}

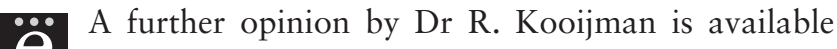
with the electronic version of this article on our website at www.jbjs.org.uk

No benefits in any form have been received or will be received from a commercial party related directly or indirectly to the subject of this article.

\section{References}

1. Malchau P, Herberts P, Soederman P, Oden A. The Swedish Total Hip Replacement Register. J Bone Joint Surg [Am] 2002;84-A(Suppl 1):2-20.

2. Joshi AB, Porter ML, Trail IA, et al. Long-term results of Charnley low-friction arthroplasty in young patients. J Bone Joint Surg [Br] 1993;75-B:616-23.

3. Charnley J. Low friction arthroplasty of the hip: theory and practice. Berlin: SpringerVerlag, 1979

4. Archibeck MJ, Berger RA, Jacobs JJ, et al. Second-generation cementless total hip arthroplasty: eight to eleven-year results. J Bone Joint Surg [Am] 2001;83-A: 1666-73.

5. Bizot P, Nizard R, Hamadouche M, Hannouche D, Sedel L. Prevention of wear and osteolysis: alumina-on-alumina bearing. Clin Orthop 2001;393:85-93.

6. Dorr LD, Wan Z, Longjohn DB, Dubois B, Murken R. Total hip arthroplasty with use of the Metasul metal-on-metal articulation: four to seven-year results. J Bone Joint Surg [Am] 2000;82-A:789-98.

7. Schmalzried TP, Fowble VA, Ure KJ, Amstutz HC. Metal on metal surface replacement of the hip: technique, fixation, and early results. Clin Orthop 1996;329 (Suppl):106-14.

8. Daniel J, Pynsent PB, McMinn DJ. Metal-on-metal resurfacing of the hip in patients under the age of 55 years with osteoarthritis. J Bone Joint Surg [Br] 2004; 86-B:177-84.

9. Capello WN, Ireland PH, Trammell TR, Eicher P. Conservative total hip arthroplasty: a procedure to conserve bone stock. Part I: analysis of sixty-six patients. Part II: analysis of failures. Clin Orthop 1978;134:59-74.

10. Freeman MA, Cameron HU, Brown GC. Cemented double cup arthroplasty of the hip: a 5 year experience with the OCLH prosthesis. Clin Orthop 1978;134:45-52.

11. Trentani C, Vaccarino F. The Patrinieri-Trentani hip joint resurface arthroplasty. Clin Orthop 1978;134:36-40.

12. Beaule PE, Le Duff M, Campbell P, et al. Metal-on-metal surface arthroplasty with a cemented femoral component: a 7-10 year follow-up study. J Arthroplasty 2004; 19(Suppl 3):17-22

13. Pearson AM, Fognet $\mathbf{P}$, Little $\mathbf{C}$. Can we prevent fractures in hip resurfacing? J Bone Joint Surg [Br] 2005;87-B(Suppl 1):41.

14. Gerard Y. Hip arthroplasty by matching cups. Clin Orthop 1978;134:25-35.

15. Shimmin AJ, Back D. Femoral neck fractures following Birmingham hip resurfacing J Bone Joint Surg [Br] 2005;87-B:463-4.

16. Little CP, Ruiz AL, Harding IJ, et al. Osteonecrosis in retrieved femoral heads after failed resurfacing arthroplasty of the hip. J Bone Joint Surg [Br] 2005;87-B:320-3.

17. Treacy RB, McBryde CW, Pynsent PB. Birmingham hip resurfacing arthroplasty: a minimum follow-up of five years. J Bone Joint Surg [Br]2005;87-B:167-70.

18. Milgram JW, Rana NA. Pathologic evaluation of the failed cup arthroplasty: a review of 32 cases. Clin Orthop 1981;158:158-79.

19. Campbell P, Mirra J, Amstutz HC. Viability of femoral heads treated with resurfacing arthroplasty. J Arthroplasty 2000;15:120-2.

20. Albery WJ, Brooks WN, Gibson SP, Hahn CE. An electrode for PN2O and PO2 analysis in blood and gas. J Appl Physio/ 1978;45:637-43

21. Hahn CE, Brooks WN, Albery WJ, Rolfe P. 02 and N2O analysis with a single intravascular catheter electrode: an in-vitro study. Anaesthesia 1979;34:263-6.

22. Brooks WN, Hahn CE, Foex P, Maynard P, Albery WJ. On-line PO2 and PN2O analysis with an in vivo catheter electrode. Br J Anaesth 1980;52:715-22. 
23. Greenbaum AR, Etherington PJ, Manek S, et al. Measurements of oxygenation and perfusion in skeletal muscle using multiple microelectrodes. J Muscle Res Cell Motil 1997;18:149-59

24. Barron DJ, Etherington PJ, Winlove CP, et al. Muscle transformation in cardiomyoplasty: the effect of conditioning and mobilisation on perfusion, oxygenation and fatigue resistance in the latissimus dorsi muscle. Eur J Cardiothorac Surg 1998:13:588-98.

25. Barron DJ, Etherington PJ, Winlove CP, Pepper JR. Regional perfusion and oxygenation in the pedicled latissimus dorsi muscle flap: the effect of mobilisation and electrical stimulation. Br J Plast Surg 1997;50:435-42.

26. Bartels EM, Fairbank JC, Winlove CP, Urban JP. Oxygen and lactate concentrations measured in vivo in the intervertebral discs of patients with scoliosis and back pain. Spine 1998;23:1-7.
27. Bibby SR, Fairbank JC, Urban MR, Urban JP. Cell viability in scoliotic discs in relation to disc deformity and nutrient levels. Spine 2002;27:2220-8.

28. Forrest N, Ashcroft, Murray D. Femoral head viability after Birmingham resurfacing hip arthroplasty: assessment using positron emission tomography [abstract]. Procs 7th EFORT Congress, 2005.

29. Trueta J, Harrison $\mathbf{M H}$. The normal vascular anatomy of the femoral head in adult man. J Bone Joint Surg [Br] 1953;35-B:442-61.

30. Gautier E, Ganz K, Krugel N, Gill T, Ganz R. Anatomy of the medial femoral circumflex artery and its surgical implications. J Bone Joint Surg [Br]2000;82-B: 679-83.

31. Notzli HP, Siebenrock KA, Hempfing A, Ramseier LE, Ganz R. Perfusion of the femoral head during surgical dislocation of the hip: monitoring by laser Doppler flowmetry. J Bone Joint Surg [Br] 2002;84-B:300-4. 